\title{
Study Protocol \\ Effects of Square-Stepping Exercise on Motor and Cognitive Skills in Autism Spectrum Disorder Children and Adolescents: A Study Protocol
}

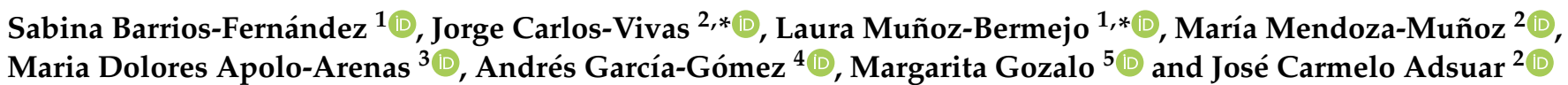

check for updates

Citation: Barrios-Fernández, S.; Carlos-Vivas, J.; Muñoz-Bermejo, L.; Mendoza-Muñoz, M.; Apolo-Arenas, M.D.; García-Gómez, A.; Gozalo, M.; Adsuar, J.C. Effects of SquareStepping Exercise on Motor and Cognitive Skills in Autism Spectrum Disorder Children and Adolescents: A Study Protocol. Healthcare 2022, 10 , 450. https://doi.org/10.3390/ healthcare 10030450

Academic Editors: Masashi Kanai and Alyx Taylor

Received: 21 January 2022

Accepted: 24 February 2022

Published: 28 February 2022

Publisher's Note: MDPI stays neutral with regard to jurisdictional claims in published maps and institutional affiliations.

Copyright: (C) 2022 by the authors. Licensee MDPI, Basel, Switzerland. This article is an open access article distributed under the terms and conditions of the Creative Commons Attribution (CC BY) license (https:// creativecommons.org/licenses/by/ $4.0 /)$
1 Social Impact and Innovation in Health (InHEALTH) Research Group, Faculty of Sport Sciences, University of Extremadura, 10003 Cáceres, Spain; sabinabarrios@unex.es

2 Promoting a Healthy Society Research Group (PHeSO), Faculty of Sport Sciences, University of Extremadura, 10003 Cáceres, Spain; mamendozam@unex.es (M.M.-M.); jadssal@unex.es (J.C.A.)

3 Department of Medical and Surgical Therapeutics, Medicine and Health Sciences College, University of Extremadura, 06006 Badajoz, Spain; mdapolo@unex.es

4 Occupational Stress, Psychopathologies and Emotional Well-Being (GRESPE) Research Group, University of Extremadura, 06006 Badajoz, Spain; agarcil9@unex.es

5 Psychology and Anthropology Department, University of Extremadura, 10003 Cáceres, Spain; mgozalo@unex.es

* Correspondence: jorgecv@unex.es (J.C.-V.); lauramunoz@unex.es (L.M.-B.); Tel.: +34-927-257460 (J.C.-V.); +34-924-387068 (L.M.-B.)

\begin{abstract}
Individuals with autism spectrum disorder (ASD) diagnoses present not only cognitive, emotional, communicative, and social challenges but also movement issues that affect their everyday activities, learning, and leisure. The use of the square-stepping exercise (SSE), a motor program initially created to strengthen the lower limbs of older adults, is spreading because of its advantages (e.g., balance and lower limb strength improvements). A study protocol to assess the SSE effects on motor, sensory, and cognitive skills in Spanish children and adolescents between 6 and 12 years old with ASD diagnoses is presented. A randomised clinical will be performed, recruiting 52 children and adolescents with ASD who will be distributed into two groups: an experimental $(n=26)$ and a control $(n=26)$ group. The SSE sessions will be held for 9 weeks (two times per week). The main variable will be balance, which will be measured with the Movement Assessment Battery for Children 2 (MABC2), and secondary outcomes will include sensory processing, attention, and executive functions. Assessments will be carried out before and at the end of the program implementation, including an additional follow up one month later. If this program obtains positive results, it should be implemented in different settings (schools, clinics, associations, etc.) to improve the quality of movement and development in children and adolescents with ASD, as it is an easy-to-use and structured tool.
\end{abstract}

Keywords: square-stepping exercise; motor skills; balance; cognitive skills; sensory processing; sensory integration; autism spectrum disorders

\section{Introduction}

\subsection{Autism Spectrum Disorders}

Conceptualising autism spectrum disorders (ASDs) is a complex task, as their definition has evolved over time [1,2]. It must be remembered that "when you know a person with ASD, you know a person with ASD", which means that each person is different because they not only have different levels of severity but also different strengths, personalities, environments and settings, and support [3,4]. Thus, ASDs are classified within the group of neurodevelopmental disorders, which also includes intellectual disabilities, communication disorders, attention-deficit/hyperactivity disorder, specific learning disorders, 
motor disorders, and other neurodevelopmental disorders [5]. ASD is characterised by persistent deficits in social communication and interaction and by restricted, repetitive patterns of behaviours, interests, or activities with clinically significant impairment in their daily functioning and participation $[5,6]$. When an individual is diagnosed with ASD, it should be specified whether there are comorbidities of intellectual or language impairment, other neurodevelopmental disorders, or medical or genetic conditions. Thus, the severity of the disorder is classified into three levels: 1st level, "supports are required"; 2nd level, "substantial supports are required"; and 3rd level, "very substantial supports are required" [5,7].

People with ASD cope with cognitive, emotional, communicative, and social challenges, including attention [8], working memory, planning, inhibition, impulsivity control or problem-solving $[9,10]$, challenges in self-control and self-regulation $[11,12]$, theory of mind $[13,14]$, issues with intersubjectivity and joint attention $[15,16]$, other challenges related to comprehension and social use of language [17,18], social skills and competence $[19,20]$ in interpreting contexts [21,22], and sensory integration issues [23-25], among others.

\subsection{Motor Impairments in Autism Spectrum Disorder}

As mentioned, the main symptoms of ASD are focused on those described in diagnostic manuals [5,26]. However, for some time now, motor performance has been the subject of different studies because motor difficulties are observed both in fine $[27,28]$ and gross motor skills and coordination [29], showing difficulties or delays in acquiring motor milestones or fundamental movement skills [30,31]. Children and adolescents with ASD have issues using the sensory inputs necessary for adequate postural control [32], which is essential for standing, walking, and performing activities of daily living [33]. Balance performance has been also studied. Deficits in sensory integration are well-documented in ASD, with implications of producing purposeful and well-adjusted movement, as the brain requires proper integration of the information from both the internal and external environment to produce appropriate motor responses to the presented challenges $[23,34]$. People with ASD present difficulties while processing the sensory information necessary for postural control, which results in increased susceptibility to postural sway under visual stimuli in comparison with somatosensory stimuli [32,35]. Regarding gait, they perform longer stance phases and shorter steps, using a greater base of support, greater hip flexion, less knee extension, and an altered contact pattern. Differences in gait cadence and hip and ankle kinetics have also been found, with reduced plantar flexor movements and increased dorsiflexion angle [36,37]. The reasons for these abnormalities include the presence of hypotonia, difficulties in sensory integration and motor planning $[23,38,39]$, and dysfunction of the basal ganglia or cerebellum $[36,37,40,41]$. Hypotonia is so closely linked to ASD that some studies even indicate that it may be a key element for the early detection of ASD [42]. Low muscle tone may be an early marker of ASD, with a more pronounced influence in younger children. Hypotonia may speed up the age of diagnosis by one and a half years on average in boys and one year in girls [43]. Moreover, hypotonia in children with ASD presents in 15-67\% of cases; is associated with other motor abnormalities, such as a higher frequency of motor stereotypies and later onset of independent walking; and could be an early marker of increased severity of autism symptomatology, leading to a lower quality of life in young children with ASD and their families. [44]. Therefore, it seems important to provide children with autism with opportunities for movement to enhance their motor, cognitive, and social development $[45,46]$.

\subsection{Square Stepping Exercise}

The square-stepping exercise (SSE) comprises the performance of movement patterns, including forward, backward, lateral, and oblique stepping, becoming progressively more complex [47]. The SSE was designed to improve reaction time during the step as well as restore balance after a stumble, as it involves the activation of the agonist and antagonist 
muscles of the lower limbs [47,48]. This program is carried out on a fine mat of $200 \times 100 \mathrm{~cm}$ divided into 40 squares of $25 \times 25 \mathrm{~cm}$, which is adapted to the individual's characteristics. Participants start with movement patterns such as walking, and little by little, they make more complex patterns that require multidirectional movements [49]. The SSE includes close to 200 diverse movement patterns, classified by difficulty into three general levels: beginner (including two sub-levels), intermediate (with three sub-levels), and advanced (with three sub-levels), but new or adapted pattern proposals could be added to improve the attention and motivation of the participants (e.g., including other body parts, colours, objects, etc.). Therefore, it can be considered a low-cost modality of exergaming, which can be developed indoors or outdoors, providing an innovative and playful sensorimotor intervention tool to develop skills in children and adolescents with ASD.

Using the SSE, motor and cognitive improvements have been found in functionality, balance, lower limb strength, flexibility and agility, attention, and memory in older adults [50,51]. It has shown its effectiveness in preventing and reducing falls [52]. It has been applied to diseases such as type 2 diabetes mellitus [53] and multiple sclerosis [54]. However, we are only aware of one study performed with pre-schooler children; the study aimed to determine whether SSE improved children's cognitive skills by recruiting a sample of 28 pre-schoolers, with 18 of them assigned to an experimental group that performed SSE three times a week for eight weeks. The data revealed statistically significant improvements between the two groups [55].

\subsection{Aim}

The SSE is an intervention that is rarely used in children [55,56], although it offers numerous advantages, such as being low cost, portable, adaptable, and modifiable, with different levels of difficulty and options to include different kinds of aids. Thus, we aim to analyse the effects of an SSE training program in motor (balance), sensory processing (sensory patterns, systems, and adaptive behaviour) and cognitive (attention and executive function) skills in children and adolescents with ASD.

We hypothesise that the SSE programme will lead to sensorimotor improvements in children with ASD because of improvements in sensory integration and balance and postural control. Moreover, because of the large component of planning, sequencing, change of criteria, and monitoring, we also expect positive results in the enhancement of attention and executive functions.

\section{Materials and Methods}

\subsection{Study Design}

A randomised controlled trial will be conducted with a 1:1 allocation ratio to experimental and control groups, following the Consolidated Standards of Reporting Trials (CONSORT) statement [57].

\subsection{Ethical Approval}

This trial was approved by the Bioethics Committee of the University of Extremadura (162/2021). Moreover, it was registered in the Clinical Trials Registry (request number: 383354) provided by the Australian New Zealand Clinical Trial Registry (https:/ / www. anzctr.org.au/) (accessed on 2 August 2021).

\subsection{Sample Size}

Assuming an alpha risk of 0.05 and a beta risk of 0.2 in a bilateral contrast, and assuming an effect size of 0.40 (large), 52 subjects (26 individuals in both the experimental and control groups) are required to achieve an $80 \%$ statistical power.

\subsection{Eligibility Criteria}

Participants will meet the following criteria: (a) age between 6 and 12 years; (b) a clinical ASD diagnosis under The Diagnostic and Statistical Manual of Mental Disorders, 
Fifth Edition [5]; (c) ability to understand and follow simple commands; (d) no inconvenience that prevents physical activity; (e) children and adolescents' voluntariness to take part in the study; and (f) provide signed informed consent form by the legal guardians. The experimental group individuals should complete at least $80 \%$ of the sessions and all the evaluations to be considered in the analysis.

\subsection{Randomisation and Blinding}

Participants will be randomly assigned to the experimental (SSE) or control (usual care) group using The Research Randomizer (http:/ / www.randomizer.org) (accessed on 8 July 2021) [58], with a computer-generated randomisation sequence (1:1). A member of the team not involved in this trial will handle this task, protecting the assignment in a password-protected computer file. Participants will be aware of which group they have been assigned to, but the researchers who will carry out the measurements and analyses will not.

\subsection{Instruments}

Movement Assessment Battery for Children 2 (MACB-2): This battery consists of (1) a standardised test composed of eight tests that assess three dimensions of movement (manual dexterity, aiming and catching, and balance), with different tests divided into three age ranges (3-6, 7-10, and 11-16 years); and (2) a behavioural observational checklist related to motor activities of daily living [59], one of the most frequently used instruments for coordination motor competency in children between 3 and 16 years old [60]. The psychometric properties are adequate, with reliability values above 0.70 on all scales, an intraclass correlation coefficient of 0.97 , minimal important difference values from 2.36 to 2.50 , and consistent validity when differentiating children with and without motor dysfunctions $[59,61]$. The balance section, which assesses static and dynamic balance through different tests for the different age ranges (Table 1), will be used for this study.

Table 1. Tests that compose the balance section according to the age ranges.

\begin{tabular}{ccl}
\hline Age Ranges & & \multicolumn{1}{c}{ Tests in That Age Range } \\
\hline $\begin{array}{c}\text { Age range 1 } \\
\text { (4-6 years) }\end{array}$ & - & Balance on one leg (best leg/worst leg) \\
& - & Jiptoe walking \\
Age range 2 & Jumping on mats \\
(7-10 years) & - Balance on one leg (best leg/worst leg) \\
& - Jump on one leg over a line (better leg/another leg) \\
\hline Age range 3 & - Balancing on two supports \\
(11-16 years) & - Backward heel-toe walking \\
& - Jump on one leg in zigzag (best leg/worst leg) \\
\hline
\end{tabular}

The Behavioural Observation Checklist: This checklist, included in the MACB-2 [59], allows the observation of specific motor skills that occur in everyday environments. It can be administered by parents, teachers, or professionals who know the child well. It can be used for children between 5 and 12 years of age and is composed of three sections. Section A is entitled "Moving in a static and/or predictable environment." It consists of 15 items and is scored on a Likert scale from 0 to 3, where 0 means "very well" and 3 means "with great difficulty". There is a response option for unobserved behaviours. Section B, "Moving in a dynamic and/or unpredictable environment", is composed of 15 items and is scored the same as section A. Section C, "Non-motor factors that may affect movement", consists of 13 dichotomous responses items (yes or no). It has a high internal consistency $(\alpha \geq 0.90)$ including a wide repertoire of motor skills that children perform in their daily lives. Its concurrent validity is moderate. Although its sensitivity is limited, it has good specificity [60]. 
Sensory Profile 2, Short Form (SSP2): This questionnaire evaluates sensory processing by providing information on different sensory patterns (seeking, avoiding, sensitivity, and registration), through the sensory systems (auditory, visual, tactile, and oral processing), obtaining information about adaptive behaviours (socioemotional and attention) in children between 3 years and 14 years and 11 months. The Spanish version consists of three versions: the children, scholar, and brief versions. The reliability values are above 0.70 on all factors and versions [62]. In this study, the children's version will be used. Its internal consistency is between adequate $(\alpha=0.72)$ and excellent $(\alpha=0.90)$, and its test-retest reliability coefficients range between 0.93 and 0.97 [62].

For the evaluation of attention and executive function, the following are proposed:

- Test on Perception of Differences (FACES), in the Spanish version [63], assesses perceptual and attentional skills using 60 graphic items consisting of schematic drawings of faces with elementary strokes. It consists of choosing which of the three faces that make up each element is different from the other two. It is a very brief test (three minutes) that can be applied to children and adolescents between 6 and 18 years old. The overall Cronbach's alpha was 0.91 , with a range of values being between 0.82 and 0.92. In the case of validity, it obtained moderate correlations with other intelligence and reasoning tests [63].

- Short Version of the Executive Functioning Questionnaire (EFECO-S) [64], which is composed of 20 items divided into five factors: emotional self-control, initiative and planning, working memory, inhibition, and organisation, which allow screening for difficulties in daily executive functioning. It can be completed by both parents and relatives and is valid for children and adolescents between 6 and 13 years of age. The Confirmatory Factor Analysis provided 5-factor solutions with good and excellent goodness of fit indices. The reliability, established through ordinal alpha, was high, and the magnitude of the correlation between the original version of the EFECO questionnaire and the short version was also high, which is an important support for validity [64].

- Rings and Interference Tests from the Neuropsychological Assessment of Executive Functions in Children (ENFEN) [65]. The ring test consists of the reproduction, on a board with three vertical axes, of a model presented on a sheet (towers task); whereas the interference test consists of a list of 39 words representing colour names (red, green, yellow, and blue) printed in ink of a different colour. The task consists of naming the ink colour of the word, inhibiting the written word (Stroop paradigm). Its results are validated for use in children and adolescents between 6 and 12 years of age. The alpha value was 0.76 , with a $95 \%$ confidence interval between 0.73 and 0.78 [65].

\subsection{Intervention}

Experimental group: Participants will perform the SSE intervention program twice a week for 9 weeks. The instructors will receive initial training on ASD (characteristics, strengths, motivation, and disruptive behaviour management techniques) and will be familiarised with the participants before starting the intervention. The training sessions will last approximately $30 \mathrm{~min}$, and their basic structure is shown in Table 2. The first activity will be a general warm-up; then, the participants will learn and execute the selected patterns for that day, and they all should be repeated 5 times. The session will finish with a cool-down. 
Table 2. Basic structure of an SSE program session.

\begin{tabular}{|c|}
\hline Warm-up (5 min) \\
\hline $\begin{array}{ll}\text { - } & \text { Motor games } \\
\text { - } & \text { Joint mobility and stretching }\end{array}$ \\
\hline Main Part (20 min) \\
\hline $\begin{array}{l}\text { - } \quad \text { Review of the patterns learnt in the previous session. } \\
\text { - } \quad \text { Learning and realisation of pattern number } X . \\
\text { - } \quad \text { Learning and realisation of pattern number } X X^{*}\end{array}$ \\
\hline
\end{tabular}

- Relaxation and comments about the session

- $\quad$ Personal hygiene

${ }^{*}$ The intervention will start with beginner level 1 (sub-level 1) patterns and will not move on to the next one until the participant can perform them successfully.

Participants will start with movement patterns such as walking, and little by little, they will make more complex patterns that will require multidirectional movements. Participants should not step on the squares' dividing lines. The instructor will mark every attempt in an individual notebook where the patterns will be registered, providing information on whether they were performed correctly, with errors or with assistance, and qualitative observations can be added. An example can be found in Figure 1.

Beginner level 1

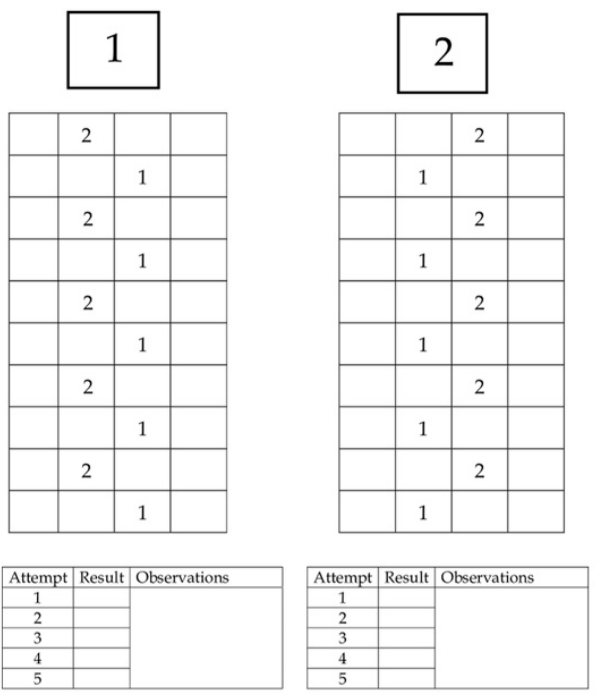

Figure 1. Example of the first two patterns of the initial level. Participants will have to reproduce these patterns 5 times, and the instructors will record the results of each attempt.

The SSE has some strengths when used with children and adolescents with ASD: (1) it is simple; the repetitive and easy-to-follow structure provides the anticipation, routine, and comprehension that some children with ASD diagnoses need, promoting errorless teaching that can help participants with self-regulation issues; (2) at the same time, it is flexible, as it offers the possibility to add additional elements, such as songs, colours, balloons, visual aids, and others, which could improve the adherence and pleasure during the training sessions. Table 3 displays the proposed progression of the SSE sessions. 
Table 3. Planned Progression of SSE intervention proposal.

\begin{tabular}{ccccc}
\hline Week & $\begin{array}{c}\text { Frequency } \\
\text { (Days a Week) }\end{array}$ & $\begin{array}{c}\text { Session Duration } \\
\text { (Minutes) }\end{array}$ & $\begin{array}{c}\text { Steps Per Sequence } \\
\text { (Number) }\end{array}$ & $\begin{array}{c}\text { Difficulty } \\
\text { (Level) }\end{array}$ \\
\hline 1 & 2 & 30 & 2 & Beginner 1 \\
2 & 2 & 30 & 4 & Beginner 2 \\
3 & 2 & 30 & 4 & Beginner 2 \\
4 & 2 & 30 & 6 & Beginner 2 \\
5 & 2 & 30 & 6 & Beginner 2 \\
6 & 2 & 30 & 6 & Intermediate 1 \\
7 & 2 & 30 & 8 & Intermediate 1 \\
8 & 2 & 30 & 8 & Intermediate 1 \\
9 & 2 & 30 & 8 & Intermediate 1 \\
\hline
\end{tabular}

Control group: Participants with ASD will continue with their usual treatments and will only be present for the assessment sessions. An additional control group of agematched, typically developed children will be added because this intervention is rarely used in children in general.

Both groups will perform evaluations at the beginning of the program, the end of the program, and a follow-up after one month following the end of the training sessions, using the described tools: MACB-2 (balance sections and behavioural checklist), SP2 (child version), the FACES, EFECO-S and Ring and Interference tasks from the ENFEN.

\subsection{Statistical Analysis}

The Statistical Package for the Social Sciences (SPSS, Version 25, IBM SPSS, Armonk, NY, USA) software will be used to perform the analyses.

Data normality and homogeneity will be assessed with the Kolmogorov-Smirnov test and Levene's test. Descriptive data will be expressed as means and standard deviation (SD) (for normally distributed variables) or medians and interquartile range (for non-normally distributed variables). Then, data will be analysed by intention-to-treat and protocol.

Intention-to-treat analysis. All randomised participants will be considered for the analysis in its group. Missing data will be imputed through multiple imputations. Repeated measures analyses of covariance adjusted by age and baseline outcomes will be used to analyse the intervention effects on the different dependent variables. The effect sizes ( $95 \%$ confidence interval) and differences will be calculated for every variable concerning the time and group $\times$ time interaction. The alpha level will be set at $p<0.05$. The data imputation for sensitivity analyses will be carried out on individuals who present data at baseline and at the end of the trial to prevent estimation bias [66].

Analysis by protocol. The analyses previously described will be carried out, but only for participants who attend at least $80 \%$ of the program sessions.

\section{Discussion}

This study will be the first to use an SSE program to improve sensory, motor, and cognitive skills in children and adolescents with ASD diagnoses. To the best of our knowledge, it will be the second in the world carried out in children [55]. We hypothesise that the SSE programme will lead to sensorimotor improvements in children with ASD because of an improvement in sensory integration and balance and postural control. Moreover, because of the high component of planning, sequencing, change of criteria, and monitoring, we also expect positive results in the enhancement of attention and executive functions.

Children and adolescents with ASD present cognitive-behavioural, socio-communicative issues and sensorimotor challenges that cause issues in both fine and motor skills and coordination. The relationship between motor performance and movement quality is closely related to the severity level of the disorder $[67,68]$. Moreover, motor $[35,37,43]$, sensory [69], cognitive [46], and socio-communicative skills impairments [45,70-72] impact the development of their occupations, including activities of daily living, learning, 
leisure, and social participation in their communities [73,74]. If this program is effective, it should be implemented in schools, clinics, and associations specialising in the education and treatment of ASD individuals because it is an innovative and easy-to-apply program, resulting in a tool for the improvement of the aforementioned skills and the inclusion of these children and adolescents.

In the long term, we also hope to increase the time spent performing physical exercise as a protective factor for their health and quality of life, adapting the activity to their characteristics and considering the barriers. In 2008, Spain ratified the Convention on the Rights of Persons with Disabilities [75], committing itself to carry out policies to improve the social participation of all people in the spheres of daily life, including school and leisure. The right of people with ASD to participate in activities is also included in the Sustainable Development Goals, being directly related to goals (3) Health and well-being, (4) Quality education, and (10) Reduction of inequalities [76]. Therefore, we hope that this project will be a small contribution to fulfilling the rights of people with ASD. One of the most important manifestations of motor skills is the practice of physical activity and sports. Several barriers to physical activity practice in children and adolescents with ASD are reported. Families consider it important for their children with ASD to exercise, but they demand support so that they can participate in these activities, as they are socially highly demanding, occur in changing contexts, and may have rules that are difficult to interpret. All the previous factors, together with their low physical competence and movement difficulties, can cause rejection [77]. Additionally, adults with ASD indicate a lack of motivation, interpersonal difficulties, and problems with sportive activities, including the type of activity, transportation or cost [78]. This limited participation in physical activities causes both preadolescents and adolescents with ASD to have a worse fitness level [79] and a higher body mass index compared with typically developed children and adolescents [80], which causes them to be at risk of suffering from pathologies related to physical inactivity, such as diabetes, hypertension, coronary and cerebrovascular diseases, and overweight/obesity, among others, which increase mortality [81,82].

\section{Conclusions}

The present study will investigate the efficacy of SSE in children and adolescents with ASD for 9 weeks to improve sensory, motor, and cognitive skills. If the efficacy of the program is demonstrated, it could be implemented in centres, entities, and associations specialised in the education and treatment of children and adolescents with ASD diagnoses.

Author Contributions: Conceptualisation, S.B.-F., A.G.-G. and J.C.-V.; methodology, J.C.-V. and J.C.A.; software, L.M.-B.; resources, M.M.-M. and M.D.A.-A.; writing-original draft preparation, L.M.-B., M.M.-M. and M.G.; writing-review and editing, S.B.-F. and A.G.-G.; visualisation, M.G. and M.D.A.-A.; supervision, J.C.A.; project administration, J.C.-V.; funding acquisition, S.B.-F. All authors have read and agreed to the published version of the manuscript.

Funding: This research received no external funding.

Institutional Review Board Statement: The study will be conducted according to the Declaration of Helsinki and was approved by the Bioethics and Committee at the University of Extremadura (code: $162 / 2021)$.

Informed Consent Statement: Informed consent will be obtained from all participants or their legal guardians.

Data Availability Statement: When the programme is carried out, the data will be available upon reasonable request.

Conflicts of Interest: The authors declare no conflict of interest. 


\section{References}

1. Artigas-Pallares, J.; Paula, I. El Autismo 70 Años Después de Leo Kanner y Hans Asperger. Rev. Asoc. Esp. Neuropsiquiatría 2012, 32, 567-587. [CrossRef]

2. Garrabe de Lara, J. El Autismo: Historia y Clasificaciones. Salud Mental 2012, 35, 257-261.

3. Cosden, M.; Koegel, L.K.; Koegel, R.L.; Greenwell, A.; Klein, E. Strength-Based Assessment for Children with Autism Spectrum Disorders. Res. Pract. Pers. Sev. Disabil. 2006, 31, 134-143. [CrossRef]

4. Urbanowicz, A.; Nicolaidis, C.; den Houting, J.; Shore, S.M.; Gaudion, K.; Girdler, S.; Savarese, R.J. An Expert Discussion on Strengths-Based Approaches in Autism. Autism Adulthood 2019, 1, 82-89. [CrossRef]

5. American Psychiatric Association (Ed.) Diagnostic and Statistical Manual of Mental Disorders: DSM-5, 5th ed.; American Psychiatric Association: Washington, DC, USA, 2013; ISBN 978-0-89042-554-1.

6. Bal, V.H.; Kim, S.-H.; Cheong, D.; Lord, C. Daily Living Skills in Individuals with Autism Spectrum Disorder from 2 to 21 Years of Age. Autism 2015, 19, 774-784. [CrossRef]

7. Mehling, M.H.; Tassé, M.J. Severity of Autism Spectrum Disorders: Current Conceptualization, and Transition to DSM-5. J. Autism Dev. Disord. 2016, 46, 2000-2016. [CrossRef] [PubMed]

8. Ruggieri, V.L. Procesos atencionales y trastornos por déficit de atención en el autismo. Rev. Neurol. 2006, 42, S051. [CrossRef]

9. Martos Pérez, J.; Paula Pérez, I. Una aproximación a las funciones ejecutivas en el trastorno del espectro autista. Rev. Neurol. 2011, 52, S147. [CrossRef]

10. Demetriou, E.A.; DeMayo, M.M.; Guastella, A.J. Executive Function in Autism Spectrum Disorder: History, Theoretical Models, Empirical Findings, and Potential as an Endophenotype. Front. Psychiatry 2019, 10, 753. [CrossRef]

11. Jahromi, L.B. Self-Regulation in Young Children with Autism Spectrum Disorder: An Interdisciplinary Perspective on Emotion Regulation, Executive Function, and Effortful Control. In International Review of Research in Developmental Disabilities; Elsevier: Amsterdam, The Netherlands, 2017; Volume 53, pp. 45-89; ISBN 978-0-12-812119-1.

12. Conner, C.M.; White, S.W.; Scahill, L.; Mazefsky, C.A. The Role of Emotion Regulation and Core Autism Symptoms in the Experience of Anxiety in Autism. Autism 2020, 24, 931-940. [CrossRef]

13. Rosello, B.; Berenguer, C.; Baixauli, I.; García, R.; Miranda, A. Theory of Mind Profiles in Children with Autism Spectrum Disorder: Adaptive/Social Skills and Pragmatic Competence. Front. Psychol. 2020, 11, 567401. [CrossRef] [PubMed]

14. Baron-Cohen, S. Theory of Mind and Autism: A Review. In International Review of Research in Mental Retardation; Elsevier: Amterdam, The Netherlands, 2000; Volume 23, pp. 169-184; ISBN 978-0-12-366223-1.

15. Nyström, P.; Thorup, E.; Bölte, S.; Falck-Ytter, T. Joint Attention in Infancy and the Emergence of Autism. Biol. Psychiatry 2019, 86, 631-638. [CrossRef] [PubMed]

16. Canal-Bedia, R. Intersubjectivity, Joint Attention and Social Referencing in Autism. A Developmental Explanation According to Ángel Rivière (Intersubjetividad, Atención Conjunta y Referencia Social En Autismo. Una Explicación Evolutiva Según Ángel Rivière). J. Study Educ. Dev. 2020, 43, 764-778. [CrossRef]

17. Lam, Y.G. Pragmatic Language in Autism: An Overview. In Comprehensive Guide to Autism; Patel, V.B., Preedy, V.R., Martin, C.R., Eds.; Springer: New York, NY, USA, 2014; pp. 533-550; ISBN 978-1-4614-4787-0.

18. Ying Sng, C.; Carter, M.; Stephenson, J. A Systematic Review of the Comparative Pragmatic Differences in Conversational Skills of Individuals with Autism. Autism Dev. Lang. Impair. 2018, 3, 239694151880380. [CrossRef]

19. Özerk, G.; Özerk, K.; Silveira-Zaldivara, T. Developing Social Skills and Social Competence in Children with Autism. Lnternational Electron. J. Elem. Educ. 2021, 13, 341-363. [CrossRef]

20. Chasson, G.; Jarosiewicz, S.R. Social Competence Impairments in Autism Spectrum Disorders. In Comprehensive Guide to Autism; Patel, V.B., Preedy, V.R., Martin, C.R., Eds.; Springer: New York, NY, USA, 2014; pp. 1099-1118; ISBN 978-1-4614-4787-0.

21. Vermeulen, M. Autism as Context Blindness; AAPC Publishing: Shawnee, KS, USA, 2012; ISBN 978-1-937473-14-3.

22. Vermeulen, P. Context Blindness in Autism Spectrum Disorder: Not Using the Forest to See the Trees as Trees. Focus Autism Dev. Disabil. 2015, 30, 182-192. [CrossRef]

23. DeBoth, K.; Reynolds, S. A Systematic Review of Sensory-Based Autism Subtypes. Res. Autism Spectr. Disord. 2017, $36,56$. [CrossRef]

24. Dellapiazza, F.; Vernhet, C.; Blanc, N.; Miot, S.; Schmidt, R.; Baghdadli, A. Links between Sensory Processing, Adaptive Behaviours, and Attention in Children with Autism Spectrum Disorder: A Systematic Review. Psychiatry Res. 2018, 270, 78-88. [CrossRef]

25. Kilroy, E.; Aziz-Zadeh, L.; Cermak, S. Ayres Theories of Autism and Sensory Integration Revisited: What Contemporary Neuroscience Has to Say. Brain Sci. 2019, 9, 68. [CrossRef]

26. World Health Organization. International Classification of Diseases for Mortality and Morbidity Statistics 11th Revision; 2019. Available online: https:/ / icd.who.int/en (accessed on 12 September 2021).

27. Lidstone, D.E.; Miah, F.Z.; Poston, B.; Beasley, J.F.; Dufek, J.S. Manual Dexterity in Children with Autism Spectrum Disorder: A Cross-Syndrome Approach. Res. Autism Spectr. Disord. 2020, 73, 101546. [CrossRef]

28. Riquelme, I.; Hatem, S.M.; Montoya, P. Abnormal Pressure Pain, Touch Sensitivity, Proprioception, and Manual Dexterity in Children with Autism Spectrum Disorders. Neural Plast. 2016, 2016, 1-9. [CrossRef] [PubMed] 
29. De Moraes, Í.A.P.; Massetti, T.; Crocetta, T.B.; da Silva, T.D.; de Mello Menezes, C.B.; Magalhães, F.H. Motor Learning Characterization in People with Autism Spectrum Disorder: A Systematic Review. Dement. Neuropsychol. 2017, 11, 276-286. [CrossRef] [PubMed]

30. Gandotra, A.; Kotyuk, E.; Szekely, A.; Kasos, K.; Csirmaz, L.; Cserjesi, R. Fundamental Movement Skills in Children with Autism Spectrum Disorder: A Systematic Review. Res. Autism Spectr. Disord. 2020, 78, 101632. [CrossRef]

31. Mohd Nordin, A.; Ismail, J.; Kamal Nor, N. Motor Development in Children with Autism Spectrum Disorder. Front. Pediatr. 2021, 9, 598276. [CrossRef] [PubMed]

32. Lim, Y.H.; Partridge, K.; Girdler, S.; Morris, S.L. Standing Postural Control in Individuals with Autism Spectrum Disorder: Systematic Review and Meta-Analysis. J. Autism Dev. Disord. 2017, 47, 2238-2253. [CrossRef] [PubMed]

33. Horak, F.B. Postural Orientation and Equilibrium: What Do We Need to Know about Neural Control of Balance to Prevent Falls? Age Ageing 2006, 35, ii7-ii11. [CrossRef] [PubMed]

34. DeBoth, K.K.; Reynolds, S.; Lane, S.J.; Carretta, H.; Lane, A.E.; Schaaf, R.C. Neurophysiological Correlates of Sensory-Based Phenotypes in ASD. Child Psychiatry Hum. Dev. 2021. [CrossRef]

35. Stins, J.F.; Emck, C. Balance Performance in Autism: A Brief Overview. Front. Psychol. 2018, 9, 901. [CrossRef]

36. Lum, J.A.G.; Shandley, K.; Albein-Urios, N.; Kirkovski, M.; Papadopoulos, N.; Wilson, R.B.; Enticott, P.G.; Rinehart, N.J. Meta-Analysis Reveals Gait Anomalies in Autism. Autism Res. 2021, 14, 733-747. [CrossRef]

37. Kindregan, D.; Gallagher, L.; Gormley, J. Gait Deviations in Children with Autism Spectrum Disorders: A Review. Autism Res. Treat. 2015, 2015, 1-8. [CrossRef]

38. Roley, S.S.; Mailloux, Z.; Parham, L.D.; Schaaf, R.C.; Lane, C.J.; Cermak, S. Sensory Integration and Praxis Patterns in Children with Autism. Am. J. Occup. Ther. 2015, 69, 1-8. [CrossRef] [PubMed]

39. Miller, L.J.; Anzalone, M.E.; Lane, S.J.; Cermak, S.A.; Osten, E.T. Concept Evolution in Sensory Integration: A Proposed Nosology for Diagnosis. Am. J. Occup. Ther. 2007, 61, 135-140. [CrossRef] [PubMed]

40. Calhoun, M.; Longworth, M.; Chester, V.L. Gait Patterns in Children with Autism. Clin. Biomech. 2011, 26, 200-206. [CrossRef] [PubMed]

41. Vilensky, J.A. Gait Disturbances in Patients with Autistic Behavior: A Preliminary Study. Arch. Neurol. 1981, 38, 646. [CrossRef] [PubMed]

42. Serdarevic, F.; Ghassabian, A.; van Batenburg-Eddes, T.; White, T.; Blanken, L.M.E.; Jaddoe, V.W.V.; Verhulst, F.C.; Tiemeier, H Infant Muscle Tone and Childhood Autistic Traits: A Longitudinal Study in the General Population: Infant Muscle Tone and Autistic Traits. Autism Res. 2017, 10, 757-768. [CrossRef]

43. Gabis, L.V.; Shaham, M.; Leon Attia, O.; Shefer, S.; Rosenan, R.; Gabis, T.; Daloya, M. The Weak Link: Hypotonia in Infancy and Autism Early Identification. Front. Neurol. 2021, 12, 612674. [CrossRef]

44. Lopez-Espejo, M.A.; Nuñez, A.C.; Moscoso, O.C.; Escobar, R.G. Clinical Characteristics of Children Affected by Autism Spectrum Disorder with and without Generalized Hypotonia. Eur. J. Pediatr. 2021, 180, 3243-3246. [CrossRef]

45. Ohara, R.; Kanejima, Y.; Kitamura, M.; Izawa, K.P. Association between Social Skills and Motor Skills in Individuals with Autism Spectrum Disorder: A Systematic Review. Eur. J. Investig. Health Psychol. Educ. 2019, 10, 276-296. [CrossRef]

46. Ludyga, S.; Pühse, U.; Gerber, M.; Mücke, M. Muscle Strength and Executive Function in Children and Adolescents with Autism Spectrum Disorder. Autism Res. 2021, 14, 2555-2563. [CrossRef]

47. Shigematsu, R.; Okura, T. A Novel Exercise for Improving Lower-Extremity Functional Fitness in the Elderly. Aging Clin. Exp. Res. 2006, 18, 242-248. [CrossRef]

48. Shigematsu, R.; Okura, T.; Nakagaichi, M.; Tanaka, K.; Sakai, T.; Kitazumi, S.; Rantanen, T. Square-Stepping Exercise and Fall Risk Factors in Older Adults: A Single-Blind, Randomized Controlled Trial. J. Gerontol. A Biol. Sci. Med. Sci. 2008, 63, 76-82. [CrossRef] [PubMed]

49. Carlos-Vivas, J.; Pérez-Gómez, J.; Delgado-Gil, S.; Campos-López, J.C.; Granado-Sánchez, M.; Rojo-Ramos, J.; Muñoz-Bermejo, L.; Barrios-Fernandez, S.; Mendoza-Muñoz, M.; Prado-Solano, A.; et al. Cost-Effectiveness of "Tele-Square Step Exercise" for Falls Prevention in Fibromyalgia Patients: A Study Protocol. Int. J. Environ. Res. Public. Health 2020, 17, 695. [CrossRef] [PubMed]

50. Teixeira, C.V.L.; Gobbi, S.; Pereira, J.R.; Vital, T.M.; Hernandéz, S.S.S.; Shigematsu, R.; Gobbi, L.T.B. Effects of Square-Stepping Exercise on Cognitive Functions of Older People: SSE and Cognition. Psychogeriatrics 2013, 13, 148-156. [CrossRef]

51. Teixeira, C.V.L.; Gobbi, S.; Pereira, J.R.; Ueno, D.T.; Shigematsu, R.; Gobbi, L.T.B. Effect of Square-Stepping Exercise and Basic Exercises on Functional Fitness of Older Adults: SSE and Functional Fitness. Geriatr. Gerontol. Int. 2013, 13, 842-848. [CrossRef] [PubMed]

52. Giannouli, E.; Morat, T.; Zijlstra, W. A Novel Square-Stepping Exercise Program for Older Adults (StepIt): Rationale and Implications for Falls Prevention. Front. Med. 2020, 6, 318. [CrossRef]

53. Shellington, E.M.; Reichert, S.M.; Heath, M.; Gill, D.P.; Shigematsu, R.; Petrella, R.J. Results from a Feasibility Study of SquareStepping Exercise in Older Adults with Type 2 Diabetes and Self-Reported Cognitive Complaints to Improve Global Cognitive Functioning. Can. J. Diabetes 2018, 42, 603-612.e1. [CrossRef]

54. Sebastião, E.; McAuley, E.; Shigematsu, R.; Motl, R.W. Feasibility Study Design and Methods for a Home-Based, Square-Stepping Exercise Program among Older Adults with Multiple Sclerosis: The SSE-MS Project. Contemp. Clin. Trials Commun. 2017, 7 200-207. [CrossRef] 
55. Ramah, N. The Effects of Square-Stepping Exercises on Cognitive Skills for Kindergarten Age Children. Sci. Mov. Health 2014, 14, 126-130.

56. Domínguez-Muñoz, A.; Carlos-Vivas, J.; Barrios-Fernandez, S.; Adsuar, J.C.; Morenas-Martín, J.; Garcia-Gordillo, M.A.; Domínguez-Muñoz, F.J. Pedagogical Proposal of Tele-Exercise Based on "Square Stepping Exercise" in Preschoolers: Study Protocol. Int. J. Environ. Res. Public. Health 2021, 18, 8649. [CrossRef]

57. Turner, L.; Shamseer, L.; Altman, D.G.; Weeks, L.; Peters, J.; Kober, T.; Dias, S.; Schulz, K.F.; Plint, A.C.; Moher, D. Consolidated Standards of Reporting Trials (CONSORT) and the Completeness of Reporting of Randomised Controlled Trials (RCTs) Published in Medical Journals. Cochrane Database Syst. Rev. 2012, 11, MR000030. [CrossRef]

58. Urbaniak, G.; Plous, S. Research Randomizer (Version 4.0) [Computer Software]. Available online: http:/ /www.randomizer.org/ (accessed on 18 June 2021).

59. Henderson, S.E.; Sugden, D.A.; Barnett, A.L.; Ruiz Pérez, L.M.; Graupera-Sanz, J.L. MABC-2: Batería de Evaluación del Movimiento Para Niños-2; PsychCorp Pearson: Madrid, Spain, 2012; ISBN 978-84-15552-81-9.

60. Banátová, K.; Psotta, R. The MABC-2 Checklist: A Review of the Psychometric Properties of A Screening Tool for Developmental Coordination Disorder. J. Occup. Ther. Sch. Early Interv. 2021. [CrossRef]

61. Wuang, Y.-P.; Su, J.-H.; Su, C.-Y. Reliability and Responsiveness of the Movement Assessment Battery for Children-Second Edition Test in Children with Developmental Coordination Disorder: Reliability and Responsiveness of the MABC-2 Test. Dev. Med. Child Neurol. 2012, 54, 160-165. [CrossRef] [PubMed]

62. Dunn, W. Sensory Profile 2 Manual; Person: San Antonio, TX, USA, 2014.

63. Thurstone, L.L.; Yela, M. Test de Percepción de Diferencias (Caras-R); TEA: Madrid, Spain, 2012; ISBN 978-84-15262-65-7.

64. Barrios-Fernandez, S.; Gozalo, M.; Amado-Fuentes, M.; Carlos-Vivas, J.; Garcia-Gomez, A. A Short Version of the EFECO Online Questionnaire for the Assessment of Executive Functions in School-Age Children. Children 2021, 8, 799. [CrossRef]

65. Portellano, J.A.; Martínez-Arias, R.; Zumárraga, L. Evaluación Del Nivel de Madurez y del Rendimiento Cognitivo En Actividades Relacionadas Con Las Funciones Ejecutivas En Niños; TEA: Madrid, Spain, 2009.

66. Cohen, J. Statistical Power Analysis for the Behavioral Sciences, 2nd ed.; L. Erlbaum Associates: Hillsdale, NJ, USA, 1988; ISBN 978-0-8058-0283-2.

67. Hannant, P.; Cassidy, S.; Tavassoli, T.; Mann, F. Sensorimotor Difficulties Are Associated with the Severity of Autism Spectrum Conditions. Front. Integr. Neurosci. 2016, 10, 28. [CrossRef] [PubMed]

68. Barrodi Sedehi, A.A.; Ghasemi, A.; Kashi, A.; Azimzadeh, E. The Relationship between the Motor Skills Level and the Severity of Autism Disorder in Children with Autism. Pedagogy Phys. Cult. Sports 2021, 25, 58-65. [CrossRef]

69. Coll, S.-M.; Foster, N.E.V.; Meilleur, A.; Brambati, S.M.; Hyde, K.L. Sensorimotor Skills in Autism Spectrum Disorder: A Meta-Analysis. Res. Autism Spectr. Disord. 2020, 76, 101570. [CrossRef]

70. Choi, B.; Leech, K.A.; Tager-Flusberg, H.; Nelson, C.A. Development of Fine Motor Skills Is Associated with Expressive Language Outcomes in Infants at High and Low Risk for Autism Spectrum Disorder. J. Neurodev. Disord. 2018, 10, 14. [CrossRef]

71. Cheung, W.C.; Meadan, H.; Xia, Y. A Longitudinal Analysis of the Relationships Between Social, Communication, and Motor Skills Among Students with Autism. J. Autism Dev. Disord. 2021. [CrossRef]

72. Holloway, J.M.; Long, T.M.; Biasini, F. Relationships Between Gross Motor Skills and Social Function in Young Boys With Autism Spectrum Disorder. Pediatr. Phys. Ther. 2018, 30, 184-190. [CrossRef]

73. Günal, A.; Bumin, G.; Huri, M. The Effects of Motor and Cognitive Impairments on Daily Living Activities and Quality of Life in Children with Autism. J. Occup. Ther. Sch. Early Interv. 2019. [CrossRef]

74. Bremer, E.; Cairney, J. The Interrelationship Between Motor Coordination and Adaptive Behavior in Children With Autism Spectrum Disorder. Front. Psychol. 2018, 9, 2350. [CrossRef]

75. Gobierno de España. Instrumento de Ratificación de la Convención Sobre los Derechos de las Personas con Discapacidad, Hecho en Nueva York el 13 de Diciembre de 2006; Boletín Oficial del Estado: Madrid, Spain, 2008; Volume 96, pp. 20648-20659.

76. The United Nations. Sustainable Development Goals. In Proceedings of the Conference on Sustainable Development (UNCSD or "Rio+20"), Rio de Janiero, Brazil, 13-22 June 2012.

77. Arnell, S.; Jerlinder, K.; Lundqvist, L.-O. Parents' Perceptions and Concerns about Physical Activity Participation among Adolescents with Autism Spectrum Disorder. Autism 2020, 24, 2243-2255. [CrossRef] [PubMed]

78. Healy, S.; Brewer, B.; Laxton, P.; Powers, B.; Daly, J.; McGuire, J.; Patterson, F. Brief Report: Perceived Barriers to Physical Activity Among a National Sample of Autistic Adults. J. Autism Dev. Disord. 2021. [CrossRef]

79. Coffey, C.; Sheehan, D.; Faigenbaum, A.D.; Healy, S.; Lloyd, R.S.; Kinsella, S. Comparison of Fitness Levels between Elementary School Children with Autism Spectrum Disorder and Age-matched Neurotypically Developing Children. Autism Res. 2021, 14, 2038-2046. [CrossRef] [PubMed]

80. Corbett, B.A.; Muscatello, R.A.; Horrocks, B.K.; Klemencic, M.E.; Tanguturi, Y. Differences in Body Mass Index (BMI) in Early Adolescents with Autism Spectrum Disorder Compared to Youth with Typical Development. J. Autism Dev. Disord. 2021, 51, 2790-2799. [CrossRef] [PubMed]

81. Kumar, B.; Robinson, R.; Till, S. Physical Activity and Health in Adolescence. Clin. Med. 2015, 15, 267-272. [CrossRef]

82. Knight, J.A. Physical Inactivity: Associated Diseases and Disorders. Ann. Clin. Lab. Sci. 2012, 42, 320-337. 